Faculdade de Ciências Econômicas UFRGS
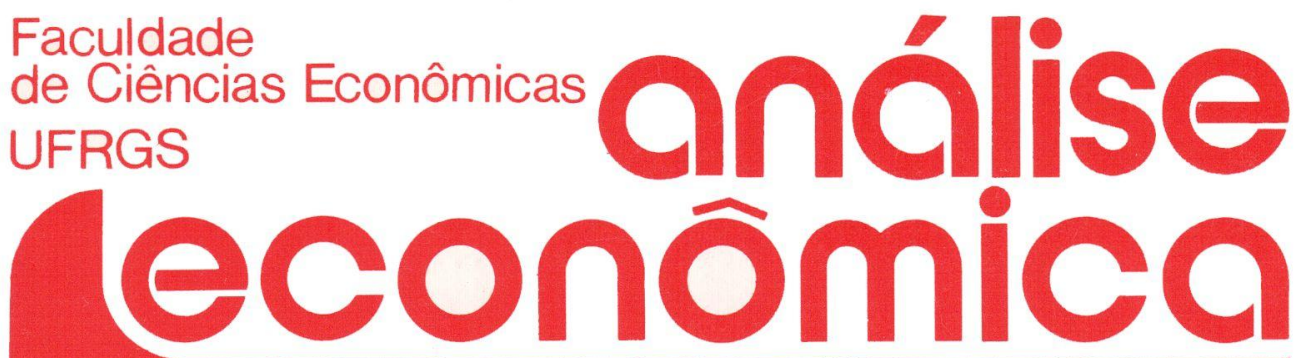

- A LINEAR MOdEL Of BALANCEd GROWTH Joanilio Rodolpho Teixeira Rodrigo Andrés de Souza Penaloza

- TEORIAS ESTRUTURALISTAS DA INFLAÇÃO

Roberto Camps Moraes

- PREÇOS EXTERNOS E EXPÓRTAÇÃO DE MANUFATURADOS Lauro Lobo Burle

- O DESENVOLVIMENTO SUECO Alfredo Marcolin Peringer

- DÉFICIT ENERGÉTICO Fabiano Augusto Nogueira Pinto

- RICARDO E O PROBLEMA SOCIAL Cezar Machado Mello

- UM SABER QUE NÃo SABE: INSTRUMENTO DE PREVISÃO Eleutério F.S. Prado

- SELEÇÃo dE PLANOS DE PRODUÇÃO PARA PEQUENOS PRODUTORES AGRICOLAS Juvir Luiz Mattuella

- PERSPECTIVAS da ECONOMIA do NORDESTE NA DÉCADA DE NOVENTA

Liana Maria da Frota Carleial

- CAIO PRADO JÚNIOR

Pedro Cezar Dutra Fonseca 
UNIVERSIDADE FEDERAL DO RIO GRANDE DO SUL Reitor. Prof. Tuiskon Dick

FACULDADE DE CIÊNCIAS ECONÔMICAS

Diretor: Prof. Walter Meucci Nique

CENTRO DE ESTUDOS E PESQUISAS ECONÔMICAS

Diretor: Reinaldo lgnácio Adams

DEPARTAMENTO DE CIÉNCIAS ECONÔMICAS

Chefe: Prof. Pedro Cezar Dutra Fonseca

CURSO DE PÓS-GRADUAÇÃO EM ECONOMIA

Coordenador: Prof. Nali de Jesus de Souza

CURSO DE PÓS-GRADUAÇĀO EM ECONOMIA RURAL

Coordenador. Prof. Atos Freitas Grawunder

CONSELHO EDITORIAL: Achyles Barcelos da Costa, Aray Miguel Feldens, Atos Freitas Grawunder, Carlos Augusto Crusius, Ernani Hickmann, João Rogério Sanson, Juvir Luiz Mattuella, Maria Imilda da Costa e Silva, Nali de Jesus de Souza, Nuno Renan Lopes de Figueiredo Pinto, Otília Beatriz Kroeff Carrion, Otto Guilherme Konzen, Paulo Alexandre Spohr, Pedro Cezar Dutra Fonseca, Reinaldo Ignacio Adams, Roberto Camps Moraes, Valter José Stülp, Yeda Rorato Crusius, David Garlow (Wharton Econometrics Forecasts Association, E.U.A.), Edgar Augusto Lanzer (UFSC), Eleutério F.S. Prado (USP), Fernando Holanda Barbosa (FGV/RJ), Gustavo Franco (PUC/RJ), Joaquim Pinto de Andrade (UnB), Juan H. Moldau (USP), Werner Baer (Univ. de Illinois, E.U.A.).

COMISSĀO EDITORIAL: Atos Freitas Grawunder, Pedro Cezar Dutra Fonseca, Reinaldo Ignacio Adams e Roberto Camps Moraes.

EDITOR: Nali de Jesus de Souza

SECRETARIA: Maria Ivone de Mello (normalização), Vanete Ricacheski (revisão de textos), Zélide Bregalda (Secretária).

FUNDADOR: Prof. Antônio Carlos Santos Rosa

Os materiais publicados na revista Análise Econômica são de exclusiva responsabilidade dos autores. É permitida a reprodução total ou parcial dos trabalhos, desde que seja citada a fonte.

Aceita-se permuta com revistas congêneres. Aceitam-se, também, livros para divulgação, elaboração de resenhas ou recensōes.

Toda correspondência, material para publicação, assinaturas e permutas devem ser dirigidos ao seguinte destinatário:

PROF. NALI DE JESUS DE SOUZA

Revista Análise Econômica

Av. João Pessoa, 52

90.040 - PORTO ALEGRE (RS), BRASIL

Telefone: (0512) 25-58-44 ramal 33

Fax: (0512) 25-5253 


\title{
SELEÇÃO DE PLANOS DE PRODUÇÃO PARA PEQUENOS PRODUTORES AGRÍCOLAS
}

Juvir Luiz Mattuella*

\begin{abstract}
SINOPSE
O objetivo deste trabalho es selecionar combinaçōes de empreendimentos agrícolas para pequenas propriedades de forma a garantir um nivel mínimo de renda prê-estabelecido, com alta probabilidade que o mesmo seja atingido. Partindo-se da premissa que o pequeno produtor tem aversão ao risco e usando-se informações de uma propriedade tipificada, desenvolveu-se um modelo de programação matemática para análise de risco a fim de determinar tais planos agricolas. Os resultados mostraram que é possivel atingir a meta de renda pré-estabelecida, bastando adotar o conjunto de atividades agrícolas que apareceram na soluçăo ótima dos modelos.
\end{abstract}

\section{INTRODUÇÃo}

A atividade agrícola distingue-se das demais atividades económicas pela complexidade de fatores aleatórios que a ela estão associados. Neste particular, o tomador de decisões enfrenta um ambiente adverso, de incertezas e riscos, estando, portanto, o processo decisório sempre cercado de insegurança, fazendo com que a renda da atividade agrícola seja instável, variando de ano para ano.

Consideram-se como situações de risco aquelas em que o produtor, por informações do passado, pode inferir que, com certa probabilidade, se repitam. Em contrapartida, a incerteza caracteriza-se por situa-

- Pesquisador do IEPE/UFRGs e Professor do Departamento de Ciências Económicas da UFRGS. Este artigo deriva de uma pesquisa financiada pelo CNPQ.

ANÁLISE ECONÓMICA

\begin{tabular}{|l|l|} 
ANO 8 & № 14 \\
\hline
\end{tabular}
NOVEMBRO/90

p.123-140 
ções em que a probabilidade do fenômeno não pode ser antecipada. Esta distinção, entretanto, torna-se extremamente artificial, pois sempre é possivel computar, embora de forma subjetiva, probabilidades para eventos ou estados do mundo real. Desta forma, a diferenciação entre risco e incerteza pode tornar-se inócua.

Os riscos enfrentados pelos agricultores, bem como o efeito dos mesmos sobre a renda agrícola esperada, variam conforme o tipo de empreendimento agrícola, as condiçōes ambientais, políticas agrícolas e arranjos institucionais. Dentro deste contexto, ao programar quais as atividades agrícolas que irá desenvolver, o produtor considera, entre outras coisas, sua disponibilidade de recursos, a perspectiva de mercado para os produtos, a aptidão do solo e, para certos casos, previsões climáticas. Assim agindo, ele estará, implicitamente, dimensionando, a priori, o tipo e intensidade de risco ao qual estará atrelado o resultado de sua atividade. Assim qualquer alteração nas condições iniciais que embasaram sua decisão poderá afetar sensivelmente o resultado esperado. Desta forma, o fator incerteza encontra-se sempre presente no resultado final do empreendimento agrícola.

De maneira geral, os fatores de risco enfrentados pelos agricultores podem ser, grosso modo, aglutinados em duas fontes: de produção e de mercado. $O$ primeiro grupo refere-se ao risco relacionado com a produtividade das atividades agrícolas devido a fatores biológicos e/ou climáticos, enquanto, no segundo, são arrolados os fatores de risco inerèntes a alterações nos preços dos produtos destas atividades, bem como mudanças nos custos de produção das mesmas, provenientes de alteraçōes nos preços dos insumos. Estas fontes de risco, para o produtor individual, são exógenas, pois ele não tem nenhum controle sobre as mesmas.

Por sua natureza, tipo de negócio e ambiente em que está inserido, o agricultor típico tem um comportamento, que o caracteriza, como uma pessoa aversa ao risco. Ele conduz seus negócios segundo a lógica econômica da racionalidade, pautando suas decisões de modo a evitar o risco, embora estas estejam sempre limitadas no conjunto de informações a ele disponiveis para tal fim. Via de regra, este tipo de comportamento conduz o produtor a preferir planos que lhe propiciem, com certa segurança, determinando nível de renda, em troca daqueles mais arriscados que, na média, poderiam oferecer um ganho maior. Planos mais seguros, geralmente, envolvem um número maior de atividades menos arriscadas, usualmente empregando tecnologias mais tradicio- 
nais e com produtividade menor em oposição à especialização e ao emprego de novas tecnologias. Além disso, os pequenos produtores agricolas podem buscar proteção contra riscos atravês da combinação de empreendimentos que utilizem intensivamente a mão-de-obra familiar e que forneçam boa parte dos produtos de subsistência da família. Face a isto, é inegável a necessidade de se desenvolver estudos que estejam relacionados com o processo de tomada de decisão, pois assim procedendo-se, ampliar-se-á o leque de possibilidades para que estes produtores programem suas atividades em um ambiente menos incerto. Assim, o presente estudo objetiva selecionar alternativas de produção para pequenos produtores rurais sob condições de risco, propiciando aos mesmos um nível de renda mínimo, previamente estabelecido, com uma alta probabilidade de que o mesmo seja atingido.

\section{MODELO ANALITIICO}

Os modelos que envolvem análise de risco e incerteza podem ser agrupados em dois segmentos: modelos bayesianos e modelos de portfólio. Os primeiros representam a aplicação da teoria de decisão bayesiana, em que o tomador das decisões tem um conhecimento completo das possiveis ações a serem seguidas e escolhe a melhor delas. Estes modelos descartam implicitamente, a possibilidade de seleção de mais de uma ação ou de combinação das mesmas. Os segundos caracterizam-se pela viabilidade de incluir, na estratégia ótima, mistura ou combinaçōes de prospectos de risco. Estes últimos são mais adequados para resolver problemas de planejamento de atividades agrícolas.

Os modelos que seguem a linha de análise de portfólio para planejamento, com aplicação para o setor agrícola, são relativamente abundantes na literatura econômica (Anderson et alii,1977; Hazell x Norton, 1986; Kennedy x Francisco, 1974). Porém, cada um deles tem suas peculiaridades e a eficiência de cada modelo está condicionada ao atendimento destas.

Dado o tipo de problema que se pretende analisar e os dados disponiveis, os modelos mais adequados para alcançar o objetivo proposto são aqueles classificados na categoria "Safety-First". Os modelos enquadrados nesta categoria caracterizam-se por assegurar, na solução ótima, a obtenção de um certo nivel de retorno previamente estabelecido, com um alto grau probabilístico. Em se tratando do setor agrícola, o 
retorno mínimo estabelecido usualmente visa a cobrir certos desembolsos, componentes do custo fixo, incluindo-se, ainda, o pagamento de empréstimos tomados ou o nivel de renda mínimo para garantir a subsistência da família do produtor. Neste caso, prossupõe-se que o agricultor, ao invés de minimizar a variância do retorno do plano agrícola ou qualquer outra medida de dispersão, está, na verdade, mais preocupado com a incerteza de obter um valor tão baixo de retorno que pode representar a falência da empresa ou a sobrevivência da familia.

Uma versão do modelo geral descrito acima foi desenvolvida por Boussard x Petit (1967) para selecionar planos agrícolas para produtores no sul da França. Esta versão denominada "foco-perda" baseia-se na hipótese de que os agricultores escolhem, entre alternativas viáveis, aquele conjunto de atividades que maximiza sua renda esperada, na condição de que a possibilidade de falência tenha uma probabilidade tão baixa de ocorrer que pode ser negligenciada. Em essência, o modelo especifica o "foco-perda" de uma atividade de risco como sendo o nivel de perda tal que o tomador de decisões ficaria surpreso se o mesmo se concretizasse na realidade.

Embora este modelo seja extremamente simples na concepção e operacionalização, apresenta algumas restriçōes quanto a certos pressupostos e paråmetros atinentes à sua formulação. Os parâmetros, tais como valor crítico de renda, nivel especificado de probabilidade, perda máxima permitida e sua distribuição entre as atividades, não têm regra fixa para determinação, isto é, não se submetem a procedimentos rigorosamente cientificos. Os valores a eles atribuídos ou podem ser arbitrários ou baseados em algum critério já consagrado pela tradição ou, ainda, por experiências empíricas passadas.

As restriçōes de ordem teórica do modelo referem-se aos pressupostos de normalidade na distribuição das receitas das atividades; independência das distribuições entre as atividades; e linearidade da função de utilidade em relaçáo à riqueza, ao menos para os niveis de renda acima do mínimo estabelecido. Os dois primeiros pressupostos não têm encontrado suporte na maioria dos estudos empíricos realizados (Anderson et alii, 1977). O último pressuposto é criticado com base no já consolidado princípio da utilidade marginal decrescente.

Pelo fato do modelo de "foco-perda" ser resolvido por programação linear, também fica condicionado às restrições atribuídas a este algoritmo de solução matemática. Seguindo a idéia do modelo de "foco- 
perda", sua operacionalização, em termos de programação matemática, pode ser expressa como segue:

$$
\begin{aligned}
\operatorname{maximizar} & Z=E(R)=\sum_{j=1}^{n} E\left(r_{j}\right) X_{j} \quad(j=1,2, \ldots, n)(1) \\
\text { dado que: } & \sum_{j=1}^{n} A_{i j} X_{j} \leqslant D_{i} \quad(i=1,2, \ldots, m)(2) \\
& s_{j} X_{j}-f_{j} L \leqslant 0 \\
& \sum_{j=1}^{n} E\left(r_{j}\right) X_{j}-M-L=0 \\
X, M, L \geqslant 0 &
\end{aligned}
$$

em que:

$$
\begin{aligned}
& E(R)=\text { renda líquida esperada; } \\
& \mathrm{A}=\text { matriz } \mathrm{i} \times \mathrm{j} \text { de coeficientes técnicos das atividades }
\end{aligned}
$$




$$
\begin{aligned}
S_{j}= & \text { vetor } j \times 1 \text { da diferença entre uma renda líquida } \\
& \text { normal e aquela que seria obtida numa situação } \\
& \text { ruim para as atividades agrícolas; } \\
f_{j}= & \text { vetor } j \times 1 \text { da fração de perda máxima permitida pa- } \\
& \text { ra cada uma das atividades agrícolas. }
\end{aligned}
$$

A restrição (3), juntamente com a definição de $s_{j}$ e $f_{j}$, objetiva a garantia de obtenção de pelos menos determinado nível de renda, concomitantemente com a dispersão da perda admissivel entre as atividades do plano. $O$ valor atribuido a $s_{j}$, garante que a renda liquida atual gerada pela j-ésima atividade deva ser, no mínimo, igual ou maior do que aquela que seria obtida numa situação extremamente adversa, com uma probabilidade próxima da unidade. Também fica evidenciado que esta restrição é satisfeita se o valor de $\mathrm{s}$, para qualquer atividade j, não exceder a uma fração $f$ da perda total admitida. A fração de perda admitida para cada atividade é dada pela razão $1 / k$. O valor atribuído a $k$ é arbitrário, embora Boussard $x$ Petit (1967), sob a hipótese da distribuição normal para a renda de cada atividade, concluiram que $\left.K^{2}\right\rangle n^{*}$ é uma condição razoável. Acontece que $\mathrm{n}^{\star}$ é o número de atividades que fazem parte da solução ótima do modelo e, portanto, não é conhecido a priori. Face a isto, estes autores, com base em diversos estudos empiricos concluiram que um valor de $\mathrm{k}$ igual a três é bastante realista.

Embora se empregue boa dose de empirismo na determinação de alguns parâmetros do modelo apresentado anteriormente, Boussard $x$ Petit (1967) e Kennedy x Francisco (1974) demonstraram que, sob certas hipóteses, é possivel se obter uma justificativa mais formal para os valores a eles atribuidos. Partindo do princípio de que as probabilidades podem ser consideradas como indicativos razoáveis para as possibilidades e, ainda, assumindo que a renda de cada atividade segue uma distribuiçăo normal e independente, estes autores demonstraram que é possivel determinar um valor probabilístico para a renda mínima não ser inferior àquela estabelecidã no modelo. A demonstração formal pode ser apresentada da seguinte maneira:

Seja $\sigma_{j}$ o desvio padrão da renda líquida da j-ésima atividade e $t_{p}$ um limite da distribuição normal para um dado valor acumulado de probabilidade $p$. Se os $s_{j}$ são escolhidos de forma que $s_{j}=\sigma_{j}$, as restrições de segurança, representadas pela equação (3) do modelo, passam a ser da seguinte forma: 


$$
\sigma_{j} t_{p} x_{j} \leqslant L / K
$$

Fazendo $K^{2} \geqslant n$, por se desconhecer $n^{*}$, e substituindo na equação (5) tem-se:

$$
\sigma_{j} x_{j} \leqslant L / t_{p} \sqrt{n}
$$

Elevando-se ambos os lados da equação (6) ao quadrado e efetuando-se a soma para todas as j-ésimas atividades, chega-se a seguinte expressão:

$$
\sum_{j=1}^{n} \sigma_{j}^{2} x_{j}^{2} \leqslant L^{2} / t_{p}^{2}
$$

Pela hipótese de que as rendas líquidas de cada atividade são independentes entre si, deduz-se que a covariância é zero, logo:

$$
V(R)=\sum_{j=1}^{n} \sigma_{j}^{2} x_{j}^{2}
$$

Substituindo-se (8) em (7) e extraindo-se a raiz quadrada de ambos os lados da equação tem-se:

$$
\sqrt{V(R)} \leqslant L / t_{p}
$$

Por definição, sabe-se que a perda máxima permitida é dada por:

$$
L=E(R)-M
$$

Substituindo-se (10) em (9) e rearranjando-se seus termos, obtémse:

$$
\{E(R)-M\} / \sqrt{V(R)} \geqslant t_{p}
$$

Note-se que a expressão (11) estabelece um intervalo de confiança para a ocorrência de uma renda igual ou maior do que aquela fixada como mínima. Em síntése, essa expressão mostra que, dada a hipótese 
de normalidade e independência na distribuição das rendas líquidas das atividades, as restrições de segurança garantem que a renda propiciada pela solução do modelo não seja menor do que o limite mínimo estabelecido (M), a umi nivel de probabilidade $p$.

\section{OPERACIONALIZAÇÃO DO MODELO}

O modelo de planejamento desenvolvido acima foi empregado para selecionar empreendimentos agricolas para pequenos produtores do municipio de Erechim. Para tanto, utilizaram-se informações constantes do trabalho realizado por GOLLO (1987) que, a partir de dados da pesquisa feita pelo Centro de Estudos e Pesquisas Econômicas da UFRGS junto a 103 produtores locais, determinou, para diferentes estratos de áreas, propriedades típicas. Entre as diversas propriedades tipificadas pela autora, selecionou-se aquela representativa para o estrato de área entre 12,5 e 25,0 hectares para servir de base para o presente estudo. Optou-se por esta propriedade típica por duas razões: a) por apresentar uma estrutura produtiva bastante diversificada tanto em termos de atividades de lavoura como de atividades criatórias; b) pelo fato de que esse tamanho de área representa a maioria das pequenas propriedades agrícolas do Estado. A congregação destes dois fatores permite que se amplie a representatividade dessa propriedade típica para outras regiōes coloniais do Estado.

Os principais empreendimentos agropastoris desenvolvidos na propriedade típica são: arroz, feijão, milho, batata-inglesa, trigo, soja, suínos, aves e gado leiteiro. As demais produções, como frutas e verduras, não foram consideradas por serem de pouca expressão.

Os coeficientes técnicos para cálculos do custo de produção foram obtidos de GOLLO (1987) e complementados com informações de outras fontes quando necessário. Para algumas atividades, foram considerados diversos processos produtivos, espelhando alternativas de produção encontradas na propriedade típica.

Para cada sistema de produção, computou-se o custo variável de produção, remunerando-se todos os fatores envolvidos, exceto a mãode-obra. Também se calculou, para cada produto das atividades antes mencionadas, duas séries históricas de receitas usando-se, para tal, os preços e produtividade do periodo de 1972/86. Na primeira destas séries, considerou-se o preço médio do ano e a produtividade respectiva, 
enquanto que na outra, usou-se a produtividade média do periodo e o preço de cada ano. Ao se estabelecer estas séries temporais de receitas, objetivou-se captar tanto flutuações dos preços como da produtividade dos empreendimentos agrícolas no tempo para, posteriormente, se estabelecer os limites de perdas especificadas no modelo.

Com as receitas e os custos de produção, calculou-se, para cada produto, a margem bruta, que consiste na diferença entre os dois. Desta forma, estimaram-se duas séries de margens brutas, uma para cada tipo de receita conforme especificado acima. Com base nos valores destas séries temporais, calculou-se a renda esperada de cada atividade (expectância) e seu respectivo desvio padrão, medidas estas usadas no modelo de programação.

A disponibilidade de recursos da propriedade tipificada foi obtida diretamente das informações prestadas pelos produtores pesquisados, conforme consta em GOLLO (1987). Em média, a propriedade típica estudada dispõe de 2 ha de pasto natural; 5,83 ha de pasto cultivado, sendo que destes, 0,46 ha são com forrageiras; 16,12 ha de terra para cultivo no verão; 10,75 ha de terra para cultivo no inverno. A mão-deobra familiar, expressa em equivalente/homem, perfaz um total de $1.105,30$ horas por bimestre. A disponibilidade de tração mecânica em horas/trator por bimestre è de 50 horas, enquanto que a tração animal é de 264 horas de equivalente junta de bois. As disponibilidades foram distribuídas por períodos para conformar o modelo de programação matemática às demandas de recursos ao longo do ciclo ca atividade agrícola.

A renda minima foi outro parâmetro a ser determinadō para atender a formulação do modelo. Neste particular, optou-se como minimo de renda o necessário para a subsistência da família do produtor, ou seja, para atender os gastos mais prementes como: alimentação, vestuário e saúde. Como não se tinha informaçōes a respeito destes gastos para as famílias dos produtores pesquisados, optou-se por estimá-los usando-se, para tal, informações colhidas em outras pesquisas realizadas pelo IE$\mathrm{PE}$ no meio rural. Após examinar diversas pesquisas realizadas em municípios gaúchos na década de 70, escolheram-se dados levantados no municipio de Cruzeiro do Sul para servirem de estimativas, pois seu meio rural guarda certa similaridade com o de Erechim, o que assegura a representatividade das informaçōes necessárias. Ao analisar o consumo e renda neste município SKRABA (1980), constatou que os gastos 
com alimentação, saúde e vestuário, para uma família média de 5,82 pessoas, eram equivalentes a $\operatorname{Cr} \$ 6.015,22$ por ano. Este parâmetro foi utilizado para estimar o nivel de renda mínima para compor o modelo de programação. Todos os valores monetários foram ajustados para cruzeiros de maio de 1990, pelo Índice de Preços - Disponibilidade Interna, da Fundação Getúlio Vargas.

\section{RESULTADOS}

A partir da concepção básica do modelo descrito anteriormente, formularam-se três situações diferentes para selecionar a combinação ótima de empreendimentos para a propriedade típica. A descrição de cada uma destas formulações e os resultados obtidos serão apresentados a seguir.

\subsection{Modelo Básico}

Este modelo foi concebido de forma a representar a situação de escolha de alternativas de produção sob a hipótese de ausência de risco. Neste caso, a renda esperada de cada atividade ocorreria com uma probabilidade igual a unidade. Os resultados obtidos neste modelo servem de referencial para as demais situaçōes onde o fator risco é levado em consideração.

$\mathrm{Na}$ formulação especificaram-se todas as alternativas de produção desenvolvidas na propriedade típica e o conjunto de restrições relativas às disponibilidades existentes na mesma. Não se impôs nenhuma outra restrição ao modelo, nem mesmo limite minimo de renda a ser atingido. Assim, a solução do modelo busca encontrar valores para as variáveis componentes da função objetivo (atividades agrícolas) de tal forma que se obtenha um valor máximo para a mesma, conquanto sejam satisfeitas as restrições das disponibilidades de recursos.

O conjunto de atividades do plano ótimo, como pode ser visto na tabela 1, compreende a produção de batata-inglesa, mandioca, soja e trigo. Nenhuma atividade criatória foi competitiva com as de lavoura. 


\section{TABELA 1 - CUSTO DE OPORTUNIDADE E NIVEL DAS ATIVI- DADES AGRÍCOLAS DA SOLUÇÃO ÓTIMA DO MO- DELO BÁSICO}

\begin{tabular}{lccr}
\hline \multicolumn{1}{c}{ Atividades } & Unidade & $\begin{array}{c}\text { Nivel da Atividade } \\
\text { Na Soluçáo Otima } \\
\text { (em unidades) }\end{array}$ & $\begin{array}{c}\text { Contribuição Marginal } \\
\text { A Função Objetivo } \\
\text { (em Cr\$) }\end{array}$ \\
\hline Arroz & ha & 0,00 & $-32.291,94$ \\
Batata-inglesa & ha & 6,78 & 0,00 \\
Feijão (safrinha) náo mecanizado & ha & 0,00 & $-83.920,35$ \\
Feijão não mecanizado & ha & 0,00 & $-38.258,10$ \\
Mandioca & ha & 0,15 & 0,00 \\
Milho não mecanizado & ha & 0,00 & $-60.616,00$ \\
Milho mecanizado & ha & 0,00 & $-55.996,14$ \\
Soja náo mecanizada & ha & 0,00 & $-16.273,75$ \\
Soja mecanizada & ha & 8,36 & 0,00 \\
Trigo não mecanizado & ha & 0,00 & $-33.789,98$ \\
Trigo mecanizado & ha & 8,31 & 0,00 \\
Milho x Soja (consorciaçáo) & ha & 0,00 & $-33.230,36$ \\
Bovinos & UB & $-65.605,82$ \\
Suinos & US & 0,00 & $-32.325,98$ \\
Aves & UA & 0,00 & $-1.115,50$ \\
\hline
\end{tabular}

FONTE: Dados da pesquisa.

Notas: a) UB $=202 \mathrm{Kg}$ de carne animal vivo e 2000 litros de leite por ano;

b) $U S=593,50 \mathrm{~kg}$ de animal vivo por ano;

c) $U A=75 \mathrm{Kg}$ de carne animal vivo e 75 dúzias de ovos.

A implementação do plano obtido na solução do modelo permitiria ao produtor auferir uma renda liquida de $\operatorname{Cr} \$ 1.832 .219,00$.

Atualizando-se os gastos com alimentação, saúde e vestuário estimados para uma família em Cruzeiro do Sul em maio de 1980, a renda minima do produtor deveria, para atendê-los, ser de $\mathrm{C} \$ 276.891,00$ por ano. Comparando-se esta renda minima com a renda obtida na solução ótima do modelo, nota-se que esta última é 6,6 vezes maior do que a primeira. Assim, em um ambiente isento de risco, o produtor teria plena garantia de poder atender os gastos mínimos com a manutenção de sua família.

Os valores da última coluna da tabela 1 podem ser interpretados como sendo o efeito na função objetivo, se uma unidade da respectiva. 
atividade fosse forçada a entrar no plano ótimo. Exemplificando, se o produtor desejasse incluir no plano ótimo um hectare de arroz sua renda iria diminuir em $\mathrm{Cr} \$ 32.291,94$ (o valor da função objetiva diminuiria deste valor).

Os recursos disponiveis que foram esgotados referem-se às horas/trator no bimestre dezembro/janeiro e à mão-de-obra nos bimestres outubro/novembro e dezembro/janeiro. Estes recursos reduziram a utilização da terra no período de inverno em cerca de $50 \%$ da disponibilidade. Por outro lado o solo foi praticamente todo cultivado para a soja de verão, principalmente aquele passivel de ser mecanizado. $O$ produtor poderia pagar até $\mathrm{Cr} \$ 521,34$ e $\mathrm{C} \$$ \$97,95 para ter uma unidade adicional de mão-de-obra e hora/trator, respectivamente, neste periodo critico. Estes seriam os respectivos custos de oportunidade para o produtor destes fatores na época de sua escassez.

A carência de mão-de-obra observada no período da colheita dos cultivos de inverno e preparo do solo para o plantio das culturas de verão, tende a favorecer àquelas atividades poupadoras de trabalho. Assim, os sistemas produtivos que empregam tração animal ou aqueles que, pela sua natureza, são intensivos em mão-de-obra, como a atividade gado de leite, se forem forçadas a entrar no plano ótimo reduziriam sensivelmente o nivel de renda esperado.

\subsection{Modelo com Risco Parcial}

Em oposição ao modelo anterior, neste modelo admite-se a possibilidade de que a margem líquida esperada dos empreendimentos possa ocorrer com um certo grau de probabilidade. Em assim, se procedendo, procurou-se inserir na seleção do plano ótimo o fator risco, que sempre está presente na tomada de decisão na atividade agrícola.

Adicionou-se à modelagem matemática anterior, um conjunto de restriçōes, denominadas de segurança, que asseguram ao produtor a obtenção de uma renda mínima especificada, com certo grau de probabilidade. Este conjunto de restrições transforma o modelo de programação determinístico em probabilístico, significando que o resultado econômico da implementação do plano ótimo nele obtido, tem chance de ocorrer, porém, dentro do limite de probabilidade estabelecido. No modelo básico, analisado anteriormente, implicitamente tinha-se assumido que os retornos das atividades, e portanto o resultado do plano ótimo, se verificariam com plena certeza. Esta hipótese é abandonada no pre- 
sente modelo, pois a receita esperada dos empreendimentos tem embutido um componente de risco, cuja fonte é a variação do preço do produto. O retorno dos empreendimentos foi determinado considerando-se, no lado da receita, a produtividade constante, porém os preços variando conforme a série histórica 72/86. O desvio-padrāo do retorno de cada empreendimento foi usado para estabelecer as restrições de segurança, procedimento este que, conforme demonstrado na conceituação do modelo, garante a obtenção da renda de subsistência com um nível de probabilidade de $84 \%$.

O plano ótimo obtido com a solução deste modelo é apresentado na tabela 2, compreende as seguintes atividades agrícolas: batata-inglesa, mandioca, soja, trigo, gado leiteiro, suínos e aves. Comparando-se este resultado com o do modelo anterior, pode-se notar que houve um sensivel aumento no número de empreendimentos que passaram a fazer parte do plano ótimo. Aliás, isto é consistente com o princípio de que para reduzir o risco, é necessário diversificar a produção. Atividades que não eram competitivas sob a suposição de certeza nos retornos,

\section{TABELA 2 - CUSTO DE OPORTUNIDADE E NIVEL DAS ATIVIDA- DES NA SOLUÇÃO ÓTIMA DO MODELO COM RISCO RESTRITO}

\begin{tabular}{lccr}
\hline \multicolumn{1}{c}{ Atividades } & Unidade & $\begin{array}{c}\text { Nivel da Atividade } \\
\text { Na Solução Ótima }\end{array}$ & $\begin{array}{r}\text { Contribuiçăo Marginal } \\
\text { A Funçăo Objetivo }\end{array}$ \\
\hline Arroz & ha & 0,00 & $-8.230,28$ \\
Batata-inglesa & ha & 2,02 & 0,00 \\
Feijão (safrinha) não mecanizado & ha & 0,00 & $-55.081,49$ \\
Feijão não mecanizado & ha & 0,00 & $-29.011,10$ \\
Mandioca & ha & 2,95 & 0,00 \\
Milho não mecanizado & hą & 0,00 & $-26.777,90$ \\
Milho mecanizado & ha & 0,00 & $-14.931,97$ \\
Soja não mecanizada & ha & 2,03 & 0,00 \\
Soja mecanizada & ha & 8,36 & 0,00 \\
Trigo não mecanizado & ha & 0,00 & $-47.301,76$ \\
Trigo mecanizado & ha & 8,31 & 0,00 \\
Milho x Soja (consorciaçáo) & ha & 0,00 & $-4.857,33$ \\
Bovinos & UB & 3,69 & 0,00 \\
Sulnos & US & 2,50 & 0,00 \\
Aves & UA & 3,00 & 0,00 \\
\hline
\end{tabular}

FONTE: Dados da pesquisa. 
como as criatórias, agora se tornaram viáveis sob a perspectiva de minimização de risco. $O$ ingresso destas atividades no plano ótimo é um indicativo de que seu nível de risco, em relação às demais, é menor.

A implementação do plano geraria uma renda de $\mathrm{C} \$ 1.096 .601,50$ que seria 3,9 vezes maior do que aquela do limite minimo estabelecido. Entretanto, a maior diversificação de atividades, condições necessárias para reduzir risco, faz com que a renda esperada seja $40 \%$ menor do que aquela do modelo anterior. $O$ fator terra foi limitante no periodo de verão, quando o total disponivel foi utilizado com cultivos desta estação. No inverno, porém, sobrou cerca de $12 \%$ da disponibilidade programada. Da terra passivel de ser mecanizada, $99 \%$ foi utilizada, enquanto a não mecanizável foi ocupada em apenas $75 \%$.

A atividade gado de leite esgota a disponibilidade de pastagem natural. Este recurso limita, portanto, a possibilidade de expansão deste empreendimento, desde que seja mantida a atual estrutura produtiva da propriedade típica.

Novamente a mão-de-obra, no periodo da colheita dos cultivos de inverno e preparo do solo para os de verão (outubro/novembro), tornouse fator limitante. $O$ custo de oportunidade deste fator para o produtor, no período crítico, é de $\mathrm{Cr} \$ 757,17$ que, em última análise, seria o valor da jornada de trabalho que o contratante estaria disposto a pagar. A disponibilidade de horas/trator esgota-se apenas no bimestre abril/maio, e tem um custo de oportunidade de $\mathrm{Cr} \$ 1.898,45$. Uma disponibilidade maior destes dois recursos nestes periodos críticos permitiria uma meIhor combinação de empreendimentos, com aproveitamento integral do recurso terra tanto no inverno como no verão.

\subsection{Modelo de Risco Integral}

Entende-se, neste modelo, como risco integral aquele inerente à produção e aos preços de venda do produto. Ele foi incorporado ao modelo através da estimativa da receita esperada para cada atividade agricola e de seu respectivo desvio padrão, obtido da série temporal de 15 anos de produtividade e preços. Espera-se que esta série temporal permita captar as oscilações de mercado, bem como variações na produção devido a fenômenos climáticos.

A forma estrutural do modelo é igual àquele com risco parcial, porém com valores diferentes para as variáveis da função objetivo e nas 
restrições de segurança. Manteve-se, também, o mesmo nivel de probabilidade para que a receita seja superior à mínima estabelecida.

As informaçōes contidas na tabela 3 mostram que a solução do modelo ampliou ainda mais o leque de empreendimentos que integram o plano ótimo. $O$ arroz, por exemplo, que nos modelos anteriores não constava do plano, agora passou a integrá-10. Os demais produtos que também fazem parte da solução ótima do modelo são: batata-inglesa, mandioca, soja, trigo, suínos, aves e gado leiteiro. Estes empreendimentos gerariam uma renda esperada de $\mathrm{Cr} \$ 774.126,72$ que é cerca de $42 \%$ daquela do plano sem risco e $70 \%$ daquela com risco parcial. Notase, pois, urna clara correlação entre risco e diversificação da atividade agrícola, que, em última análise, se reflete na renda esperada.

\section{TABELA 3 - CUSTO DE OPORTUNIDADE E NÍVEL DAS ATIVIDA- DES NA SOLUÇÃO ÓTIMA DO MODELO COM RISCO INTEGRAL}

\begin{tabular}{lccc}
\hline \multicolumn{1}{c}{ Atividades } & Unidade & $\begin{array}{c}\text { Nivel da Atividade } \\
\text { Na Solução Ótima }\end{array}$ & $\begin{array}{c}\text { Contribuição Marginal } \\
\text { A Função Objetivo }\end{array}$ \\
\hline Arroz & ha & 5,17 & 0,00 \\
Batata-Inglesa & ha & 2,43 & 0,00 \\
Feijão (safrinha) não mecanizado & ha & 0,00 & $-27.814,63$ \\
Feijão náo mecanizado & ha & 0,00 & $-15.015,13$ \\
Mandioca & ha & 2,94 & 0,00 \\
Milho não mecanizado & ha & 0,00 & $-26.803,18$ \\
Milho mecanizado & ha & 0,00 & $-15.576,69$ \\
Soja não mecánizada & ha & 0,00 & $-7.625,91$ \\
Soja mecanizada & ha & 4,82 & 0,00 \\
Trigo não mecanizado & ha & 0,00 & $-16.674,10$ \\
Trigo mecanizado & ha & 8,36 & 0,00 \\
Milho x Soja (consorciação) & ha & 0,00 & $-5.808,81$ \\
Bovinos & UB & 3,69 & 0,00 \\
Suinos & US & 2,50 & 0,00 \\
Aves & UA & 3,00 & 0,00 \\
\hline
\end{tabular}

FONTE: Dados da pesquisa.

Observa-se, também, que cultivos intensivos em mão-de-obra como o feijão e o milho, sistematicamente são excluídos do plano ótimo, pois não são competitivos com os demais produtos programados. 
Porém, se forem comparados os valores da contribuição marginal destes produtos nos três modelos, pode-se observar que eles vêm caindo, em valor absoluto, à medida que o grau de risco aumenta. Este resultado indica uma tendência dos empreendimentos agrícolas a se igualarem, em termos de competitividade à medida que o fator risco é incorporado à seleção de alternativas de produção. Entretanto, as disponibilidades de recursos e sua distribuição ao longo do ciclo agrícola pode, eventualmente, eliminar esta tendência de competitividade equilibrada. No presente modelo, a rigidez da restrição de mão-de-obra em determinados periodos do ciclo agricola pode estar favorecendo determinadas atividades a comporem o plano ótimo em detrimento de outras que, talvez, poderiam ser beneficiadas se houvesse a possibilidade de se contratar trabalho nos períodos críticos.

No que tange ao uso dos fatores de produção confirmou-se, embora não integralmente, o mesmo resultado do modelo anterior. $O$ recurso terra é totalmente utilizado no verão, ficando parcialmente ocioso no inverno. Esgotou-se, também, a disponibilidade de pastagem natural. A mão-de-obra é plenamente utilizada nos bimestres de agosto/setembro e abril/maio. No primeiro, ocorre a colheita dos cultivos de inverno e o plantio dos de verão, enquanto que, no segundo, tem-se a situação inversa.

\section{CONCLUSÕES}

Os resultados da análise mostram que, mesmo sob condições adversas, a pequena produção agrícola é uma atividade econômica factível. É possivel de se obter planos agrícolas, dentro do leque atual de alternativas de produção das pequenas propriedades pesquisadas, capazes de oferecer um retorno ao produtor mais do que suficiente para o sustento mínimo de sua família. A renda estimada, em todos os planos selecionados em cada um dos modelos, sempre foi superior àquela estabelecida como minimo de subsistência.

À medida que crescentes graus de risco são considerados na escolha dos empreendimentos, o plano ótimo tende a ser mais diversificado, porém, com um retorno menor, mostrando uma nitida correlação entre segurança e rentabilidade. Isto acontece, basicamente, porque as atividades agricolas menos rentáveis geralmente são aquelas que também possuem menor variabilidade, tanto nos preços como nas produti- 
vidades, tendo, desta forma, retornos relativamente estáveis ao longo do tempo. Assim, quando a seleção dos planos agricolas objetiva minimizar perdas, estas atividades são ascendentes sobre aquelas que, embora mais rentáveis, apresentam grandes oscilações nos retornos. Também fica evidenciado que a diversificação é fator de segurança. Portanto, se o produtor buscar primeiramente a garantia de obter certo ganho e não a maximização do mesmo, deve evitar a especialização e estruturar o sistema de produção de sua propriedade de forma a completar um maior número possível de empreendimentos.

Constatou-se que, com exceção da disponibilidade de terra e mãode-obra em certos períodos críticos, os demais recursos existentes na propriedade típica são mais do que suficientes para implementar os planos selecionados. Desta forma, os produtores abrangidos pelo estudo poderiam colocar em prática estes planos simplesmente realocando os recursos já existentes em suas propriedades. Além disso, com a reestruturação da produção, alguns destes recursos ficariam ociosos, podendo serem aproveitados para outros fins ou terem sua disponibilidade reduzida.

Finalmente, cabe enfatizar que os resultados obtidos são válidos para as propriedades pesquisadas e representadas pela situação típica, dentro dos condicionantes de recursos disponíveis e tecnologia empregada, não havendo garantias de que os mesmos se repetiriam sob outras condições.

\section{BIBLIOGRAFIA}

ANDERSON, J. R.; DILON, J. L. \& HARDAKER, J. B. Agricultural Decision Analysis. Ames, lowa. The lowa University Press, 1977. 344p. BOUSSARD, J. M. A Model of Behaviour of Farmers and its Application to Agricultural Policies. European Economic Review, v.2, n.4, 1971, p.436-61.

BOUSSARD, J. M.; PETIT, M. Representation of Farmer's Behavior Under Uncertanty With a Focus-loss Constraint. The Journal of Farm Economics, v.49, n.4, 1967, p.869-80.

DILLON, John L. \& SCANDIZZO, Pasquale L. Atitudes dos Agricultores Nordestinos de Subsistência em Relação ao Risco - Abordagem Amostral. Fortaleza. Departamento de Economia Agrícola, UFC. 1976. (Série Relatórios de Pesquisa n. 17). 
GOLLO, S.S. A Pequena Produção Agrícola: Alocação de Recursos e Combinação de Atividades nas Pequenas Propriedades do Municipio de Erechim - RS. Porto Alegre, IEPE/UFRGS. 1987. 180p. Diss. (mestr. econ: rural) UFRGS.

HAZELL, P.B.R. \& NORTON, R.D. Mathematical Programming for Economic Analysis in Agriculture. New York, Macmillan Publishing Co., 1986. 400p.

KENNEDY, J.O.S. \& FRANSCISCO, E. M. On the Formulation of Risck Constraints for Linear Programming. Journal of Agricultural Economics, v.25, n.2, 1974, p.129-44.

KONZEN, Otto G. A Pequena Propriedade Rural de Santa Catarina: Situação, Problemas e Busca de Soluções. Porto Alegre, IEPE/UFRGS, 1985. (Versão preliminar não publicada).

KONZEN, Otto G. \& MATTUELLA, Juvir L. Produção de Álcool: Competição Entre Produtos e Efeito Emprego na Agricultura do Sul do País, Análise Econômica. Porto Alegre, FCE/UFRGS, v.2, n.4, nov. 1984. KONZEN, Otto G. \& RICHTER, Humberto V. Estrutura da Produção e Renda Agrícola em Diferentes Grupos de Estabelecimentos Rurais no Brasil: Subsídios para Política Agrícola. Revista de Economia Rural, SOBER, v.20, n.2, 1982, p. 237-67.

LANZER, Edgar A. Programação Linear: Conceitos e Aplicações. Rio de Janeiro, IPEA, 1982. (Série PNPE n.4).

PASTORE, José. Decisões em Condiçōes de Incerteza na Agricultura, Porto Alegre, Anais da XII Reunião Anual da Sociedade Brasileira de Economia, SOBER, Revista de Economia Rural, ano 14, t.1, 1976, p. 147-63.

\section{ABSTRACT \\ SELECTION OF PRODUCTION PLANS FOR SMALL AGRICULTURAL PRODUCERS}

The purpose of this study is to select combinations of agricultural undertakings for small properties in order to guarantee a minimum level of pre-established income, with a high probability that it be obtained. Starting from the assumption that the small producer is risk avert and using information from a typified property, a mathematical programming model was developed so as to analyze risks, in order to determine such agricultural plans. The results have indicated that it is possible to attain the pre-established income level, provided the set of agricultural activities, that have appeared in the optimal solution of the models, are adopted. 